\title{
Letter to the Editor concerning "Does whole-spine lateral radiograph with clavicle positioning reflect the correct cervical sagittal alignment?" by Park SM et al. (Eur Spine J 24(1):57-62)
}

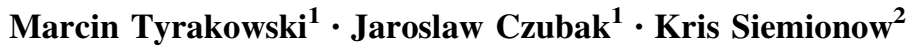

Received: 30 January 2015/Revised: 10 April 2015/Accepted: 10 April 2015/Published online: 24 April 2015

(C) The Author(s) 2015. This article is published with open access at Springerlink.com

Dear Editor,

An interesting paper was published in 2015 in the European Spine Journal [1]. We congratulate the authors addressing the important topic of evaluating the differences in the cervical alignment between standing cervical lateral radiograph and whole-spine lateral radiograph with clavicle position.

However, we would like to express our concerns regarding the aforementioned study.

First, when comparing results of measurements performed on standing cervical lateral radiographs versus on whole-spine lateral radiographs the agreement of the two methods rather than the differences between them is tested [2]. Thus, comparing differences in means of the particular parameters by use of the paired $t$ test does not seem to be an appropriate statistical approach [2-4]. According to the published guidelines other statistical methods should be used [2-4]. This may be of high importance for the McGregor line angle for which statistical significance was not reached in the study by Park et al. [1].

Second, we think that when comparing measurements based on radiographs performed in different ways testing the intraobserver reproducibility of such measurements would be valuable [2].

Marcin Tyrakowski

marcintyrak@gmail.com

1 Department of Orthopedics, Pediatric Orthopedics and Traumatology, The Centre of Postgraduate Medical Education in Warsaw, Konarskiego 13, 05-400 Otwock, Poland

2 Department of Orthopedic Surgery, University of Illinois at Chicago, 835 South Wolcott Ave, Room E-270, Chicago, IL 60612, USA
Lastly, in the "Materials and methods" section the methodology of intraobserver reliability testing is described with details; however, one important information is missing: it is not specified if all of the parameters were measured by two researchers on radiographs of all of the examined 101 patients or only on some sample of the whole study group. Such an information that is crucial for the statistical power analysis should be specified according to published guidelines of testing the reliability [2].

We believe that using an appropriate and clear methodological approach would emphasize the importance of conclusions of the study by Park et al. [1] that the true cervical sagittal alignment should be evaluated in cervical lateral radiograph with the subject in a neutral relaxed position.

Conflict of interest None.

Open Access This article is distributed under the terms of the Creative Commons Attribution 4.0 International License (http://creativecommons.org/licenses/by/4.0/), which permits unrestricted use, distribution, and reproduction in any medium, provided you give appropriate credit to the original author(s) and the source, provide a link to the Creative Commons license, and indicate if changes were made.

\section{References}

1. Park SM, Song KS, Park SH, Kang H, Riew KD (2015) Does whole-spine lateral radiograph with clavicle positioning reflect the correct cervical sagittal alignment? Eur Spine J 24(1):57-62

2. Kottner J, Audigé L, Brorson S, Donner A, Gajewski BJ, Hróbjartsson A, Roberts C, Shoukri M, Streiner DL (2011) Guidelines for reporting reliability and agreement studies (GRRAS) were proposed. J Clin Epidemiol 64:96-106

3. Bland JM, Altman DG (1986) Statistical methods for assessing agreement between two methods of clinical measurement. Lancet 1(8476):307-310

4. Rankin G, Stokes M (1998) Reliability of assessment tools in rehabilitation: an illustration of appropriate statistical analyses. Clin Rehabil 12(3):187-199 